Review Article

\title{
Mucopolysacccharidoses: From understanding to treatment, a century of discoveries
}

\author{
Roberto Giugliani ${ }^{1,2,3}$ \\ ${ }^{1}$ Departamento de Genética and Programa de Pós-Graduação em Genética e Biologia Molecular, \\ Universidade Federal de Rio Grande do Sul, Porto Alegre, RS, Brazil. \\ ${ }^{2}$ Medical Genetics Service, Hospital de Clínicas de Porto Alegre and WHO Collaborating Center for the \\ Development of Medical Genetic Services in Latin America, Porto Alegre, RS, Brazil. \\ ${ }^{3}$ Instituto Nacional de Genética Médica Populacional, Porto Alegre, RS, Brazil.
}

\begin{abstract}
After the first description of a patient recognized as a MPS case was made in 1917, several similar cases were described and identified. Observations reported in the middle of the twentieth century concerning the presence of acid mucopolysaccharides (later called glycosaminoglycans, or GAGs) in tissues and especially in urine of patients were instrumental in providing an identity for these diseases, which became referred as "mucopolysaccharidoses" (MPS). In the late 1960's it was demonstrated that MPS were caused by defects in the breakdown of GAGs, and the specific enzyme deficiencies for the 11 types and subtypes of MPS were identified thereafter. Genes involved in the MPS were subsequently identified, and a large number of disease-causing mutations were identified in each one. Although individually rare, MPS are relatively frequent as a group, with an overall incidence estimated as 1:22,000. The increased excretion of urinary GAGs observed in the vast majority of MPS patients provides a simple screening method, the diagnosis usually being confirmed by the identification of the specific enzyme deficiency. Molecular analysis also plays a role, being helpful for phenotype prediction, prenatal diagnosis and especially for the identification of carriers. As the diseases are rare and diagnosis requires sophisticated methods, the establishment of reference laboratories for MPS identification is recommended. The successful experience of the MPS Brazil Network in providing access to information and diagnosis may be considered as an option for developing countries. The development of therapeutic strategies for MPS, including bone marrow/hematopoietic stem cell transplantation (BMT/HSCT) and enzyme replacement therapy (ERT), changed the natural history of many MPS types. However, some challenges still remain, including the prevention of cognitive decline which occurs in some MPS. Newer approaches, such as intratechal ERT, substrate reduction therapy, read-through, gene therapy and encapsulated modified cells may provide a better outcome for these diseases in the near future. As early diagnosis and early treatment seems to improve treatment outcomes, and as newborn screening is now technically feasible, pilot programs (including one in progress in an area with high-incidence of MPS VI in northeastern Brazil) should provide information about its potential impact in reducing the morbidity associated with MPS diseases.
\end{abstract}

Keywords: mucopoloysaccharidoses, lysosomal diseases, enzyme replacement therapy, prenatal diagnosis, newborn screening.

\section{The Clinical Identity}

Many likely cases of mucopolysaccharidosis (MPS) were probably observed in the past, before the first description of patients recognized as MPS cases was made by Dr. Charles Hunter in 1917 (Hunter, 1917). He described two Canadian sibs, both boys, affected by a similar disease, characterized by coarse facies, large abdomen, bone dysplasia and certain other signs and symptoms. Two years

Send correspondence to Roberto Giugliani. Medical Genetics Service, Hospital de Clínicas de Porto Alegre, Rua Ramiro Barcelos 2350, 90035-903 Porto Alegre, RS, Brazil. E-mail: rgiugliani@hcpa.ufrgs.br. later, Dr. Gertrud Hurler, a German pediatrician, reported two unrelated boys with a similar picture (Hurler, 1919). She described very well the visceromegaly and bone abnormalities present in the patients.

Many similar cases were described during the following years, and the term "gargoylism" was used for some time, as it was thought that the large neck and coarse facies of the patients resembled the images of the medieval cathedral gargoyles, As observed with the patients described by Hunter and Hurler, most cases were reported with family recurrence, but in some families only boys were affected, suggesting the occurrence on of an $\mathrm{x}$-linked form in these cases. 
In 1929, the Uruguayan pediatrician Luis Morquio described a form of "familial skeletal dystrophy" affecting four of five children born to consanguineous parents from Swedish descent. This report (Morquio, 1929), along with another publication on similar cases made in the same year by the radiologist Brailsford (1929), led to the recognition of a new form of skeletal dysplasia, with no visceromegaly or cognitive impairment, later identified as Morquio syndrome (at this time, no relationship with the cases described by Hunter and Hurler was recognized).

Many years later, American ophthalmologists described an attenuated form of this syndrome, based on the corneal opacity observed in an adult patient (Scheie et al., 1962). This condition was first referred to as Scheie syndrome, but later was incorporated within the Hurler syndrome spectrum.

Subsequently, Sanfilippo et al. (1963) described in the United States a form of mental retardation associated with mucopolysacchariduria, but with less pronounced visceral and skeletal manifestations than reported in previously-described MPS patients. This form was designated Sanfilippo syndrome. In the same year, Maroteaux et al. (1963) described in France a new form of dysostosis with mucupolysacchariduria, but without cognitive impairment, which became known as Maroteaux-Lamy syndrome.

Sly and colleagues reported in 1973 an American boy with skeletal changes consistent with a mucopolysaccharidosis, hepatosplenomegaly, and granular inclusions in granulocytes. He had hernias, unusual facies, protruding sternum, thoracolumbar gibbus, vertebral deformities, and mental deficiency (Sly et al., 1973). This condition became known as Sly syndrome. It is noteworthy that although this first reported case of MPS VII was in a child, many of the subsequent cases were presented in utero as hydrops fetalis.

In the nineties, Natowicz et al. (1996) described in the United States the clinical and biochemical manifestations of hyaluronidase deficiency, a very rare type of MPS. Further cases of hyaluronidase deficiency were described more recently, suggesting that this type of MPS may be more frequent than initially tought (Imundo et al., 2011).

After the diseases were fully identified in terms of their biochemical and molecular bases, it became clear that a large clinical variability is present within each MPS type, with severe and attenuated forms and a large spectrum of clinical presentation ranging from the most severe to mildest forms. Figure 1 illustrates the clinical heterogeneity present in MPS diseases. Although the rate of progression is different from patient to patient, in all patients the disease is progressive and ultimately fatal, making these conditions a challenge for the families, doctors and health care systems.

\section{The Chemical Identity}

Even though the early clinical descriptions of Hunter and Hurler suggested that storage was present in the cases

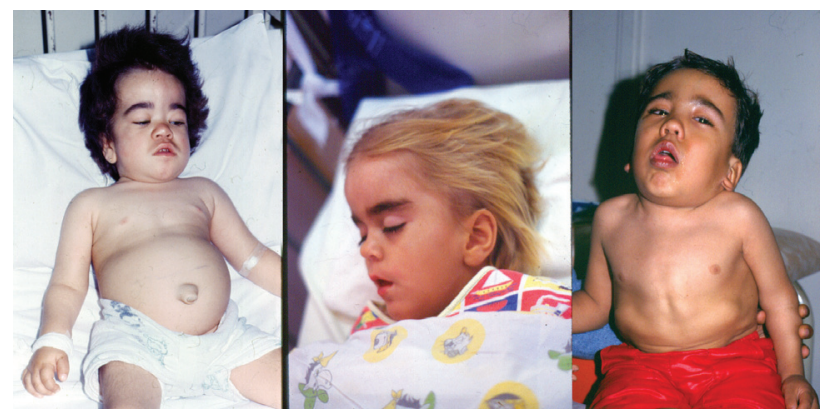

Figure 1 - Three distinct phenotypes in MPS diseases: left - MPS I patient showing visceromegaly and cognitive decline; center - MPS III B patient showing mental deterioration without major somatic fingings; right - MPS IV A patient showing skeletal dysplasia without coarse facies and visceromegaly and with normal intelligence.

reported, the nature of this storage material was only confirmed in the mid-twentieth century. Observations on the presence of acid mucopolysaccharides (later called glycosaminoglycans, or GAGs) in tissues (Brante, 1952; Costales and Garcia-Palacio, 1956) and urine (Dorfman and Lorincz, 1957; Meyer et al. 1958) of affected patients were instrumental in providing an identity for this group of diseases, which became referred to as "mucopolysaccharidoses".

In addition to the increased excretion of GAGs in urine, the study on the relative amounts of the different GAG species (Teller et al., 1962) provided a basis for attempts to classify the different diseases in this group.

\section{Summing up the Information - A Classification}

Victor McKusick, who was very active in collecting observations on heritable connective tissue disorders and in linking such observations with the concept of inborn errors of metabolism proposed by Garrod, made the first attempt to classify the mucopolysaccharidoses, considering the clinical, genetic and biochemical information available (McKusick, 1969). In his classification, six different entities were included (the Hurler, Hunter, Sanfilippo, Morquio, Scheie and Maroteaux-Lamy syndromes), based mainly on the clinical characteristics and chemical composition of urinary GAGs. Although the Hunter syndrome overlaps considerably with the Hurler syndrome in terms of clinical and biochemical aspects, it was considered a distinct entity because the mechanism of inheritance was $\mathrm{X}$-linked recessive, while the Hurler syndrome and all the other MPS were inherited as autosomal recessive traits.

\section{The Understanding of the Basic Defect}

Although it was then known that abnormal amounts of GAGs were accumulated in MPS patients, the demonstration that the problem was in the degradation pathway was confirmed only in 1968 by the group of Elisabeth Neufeld (Fratantoni et al., 1968a). Shortly thereafter this group also provided a major contribution to the understand- 
ing of the basic defect underlying MPS by performing informative cell complementation studies. When co-cultivating cells from patients with different MPS types, the occurrence of cross-correction was observed when such cells were from patients with MPS I and MPS II (Fratantoni et al., 1968b), and also in all mixes of MPS types, except when cells from patients with MPS I (Hurler) and MPS V (Scheie) were mixed. The conclusion was that patients with MPS I and MPS V, who were identified as belonging to the same cell complementation group, had the same basic defect. These experiments, in showing the uptake of correcting factors by deficient cells, provided also a rationale for therapies, such as bone marrow transplantation and enzyme replacement therapy.

The decade of the 1970s was marked by the search for specific enzyme deficiencies present in the different MPS types. Each of these enzymes was normally involved with a different step in the degradation of a particular GAG within the lysosomes of cells, and the MPS diseases were thus recognized as examples of lysosomal storage diseases. These enzyme studies confirmed that MPS I and MPS V are the severe and the attenuated ends of the spectrum of the same disease (MPS I, $\alpha$-iduronidase deficiency) (Bach et al., 1972), that the MPS III phenotype could be caused by four different enzyme defects, and MPS IV by two different enzyme defects. A consequence of the identification of specific enzyme deficiencies was that the classification of MPS was completely modified (Table 1).

\section{Molecular Genetics of MPS}

Following enzyme identification, the next cycle of discoveries on MPS, had its focus on the identification of disease causing genes. This started in 1987 with the identification of the gene implicated in MPS VII (Oshima et al.,
1987) and was completed only in 2006 with the identification of the gene for MPS III C (Fan et al., 2006). The MPS are largely heterogeneous regarding gene defects, with deletions, rearrangements and a large number of different mutations found in each MPS type. A genotype-phenotype relationship is generally observed, with a trend for missense mutations leading to less severe manifestations when compared to nonsense mutations and large gene rearrangements, but prediction of the clinical course from molecular findings is sometimes difficult to make on the individual basis.

\section{Epidemiology}

MPS are rare diseases, with data on the incidence of individual types available for only a few countries and regions. The overall incidence is estimated as 1 in 22,000 individuals considering all MPS types (Meikle et al., 1999; Poorthuis et al., 1999). The fact that MPS are clinically very heterogeneous leads us to infer that the frequency of these diseases should be higher than presently estimated, as many more attenuated cases may remain undiagnosed. The results of pilot screening programs for another lysosomal storage disease (Fabry disease) seem to confirm this prediction (Spada et al., 2006; Hwu et al., 2009; Lin et al., 2009). The relative frequency of each MPS type in Brazil indicates that MPS II is the most frequent one, followed by MPS I and MPS VI (unpublished data from the MPS Brazil Network).

\section{A Guide to the Diagnosis of MPS}

The recognition that almost all MPS patients present mucopolysachariduria, which may be easily identified by qualitative and quantitative methods, provided a simple

Table 1 - Classification of mucopolysaccharidoses.

\begin{tabular}{|c|c|c|c|c|c|}
\hline MPS & Name & Increased GAGs & Inheritance & Enzyme deficiency & Gene location \\
\hline I & $\begin{array}{l}\text { Hurler, Hurler-Scheie } \\
\quad \text { or Scheie }\end{array}$ & $\mathrm{HS}+\mathrm{DS}$ & autosomal recessive & $\alpha$-duronidase & $4 \mathrm{p} 16.3$ \\
\hline II & Hunter & $\mathrm{HS}+\mathrm{DS}$ & $\mathrm{X}$-linked recessive & Iduronate sulfatase & $\mathrm{Xq} 28$ \\
\hline III A & Sanfilippo A & HS & autosomal recessive & Heparan-N-sulfatase & $17 \mathrm{q} 25.3$ \\
\hline III B & Sanfilippo B & HS & autosomal recessive & $\alpha$-N-acetylglucosaminidase & $17 \mathrm{q} 21.1$ \\
\hline III C & Sanfilippo C & HS & autosomal recessive & AcetylCoA $\alpha$-glucosamine acetyltransferase & $14 \mathrm{p} 21$ \\
\hline III D & Sanfilippo D & HS & autosomal recessive & $\mathrm{N}$-acetylglucosamine 6-sulfatase & $12 \mathrm{q} 14$ \\
\hline IV A & Morquio A & $\mathrm{KS}$ & autosomal recessive & Galactosamine-6-sulfate sulfatase & $16 \mathrm{q} 24.3$ \\
\hline IV B & Morquio B & $\mathrm{KS}$ & autosomal recessive & $\beta$-galactosidase & $3 \mathrm{p} 21.3$ \\
\hline$(\mathrm{V})$ & \multicolumn{5}{|c|}{ Scheie syndrome, initially proposed as type V, was recognized to be the attenuated end of the MPS I spectrum } \\
\hline VI & Maroteaus-Lamy & DS & autosomal recessive & $\mathrm{N}$-acetylgalactamine 4-sulfatase & $5 q 11-q 13$ \\
\hline VII & Sly & $\mathrm{HS}+\mathrm{DS}$ & autosomal recessive & $\beta$-glucuronidase & $7 \mathrm{q} 21.11$ \\
\hline (VIII) & \multicolumn{5}{|c|}{$\begin{array}{l}\text { An enzyme defect was found and proposed as MPS VIII, but shortly thereafter recognized as a laboratory pitfall; the proposal was with- } \\
\text { drawn }\end{array}$} \\
\hline IX & Natowicz & Hyaluronan & autosomal recessive & Hyaluronidase 1 & $3 \mathrm{p} 21.3$ \\
\hline
\end{tabular}


screening test for these diseases (Pennock, 1976; Piraud et al., 1993). Even though the identification of the predominant types of GAGs excreted in urine provides important additional information about the most probable MPS type, the final diagnosis is based on the identification of the specific enzyme deficiency. This could be achieved by analysis using cultured fibroblasts, plasma or peripheral blood leukocytes, the last one usually being the preferred material for the test. The use of dried blood spots (DBS) as enzyme source is increasingly being used (Civallero et al., 2006), but it is still recommended that positive results obtained using DBS are confirmed through leucocyte analysis.

The identification of the gene defect is not required for diagnosis (whenever the enzyme assay is available) but can be helpful for phenotype prediction and for the identification of carriers. Carriers frequently exhibit an enzyme activity in between the ranges of affected patients and normal controls, but some overlap is usually observed (Schwartz et al., 2009). Carrier identification by genetic analysis is particularly important for MPS II, the X-linked form of MPS, to allow appropriate genetic counseling.

Prenatal diagnosis for MPS was performed even before the enzyme deficiencies were identified, as increased GAGs could be detected in the amniotic fluid of affected fetuses (Fratantoni et al, 1969) in families which had a previous MPS case. However, this method was not generally reliable and was not applicable to all MPS (e.g. Morquio disease). Much more accurate prenatal diagnosis became available once the enzyme defects were known, and amniotic fluid cells, chorionic villi or cord blood could be used as a source for measuring enzyme activity. Molecular analysis could now be helpful in providing faster results in families where a mutation has already been identified in an index case. Figure 2 presents a suggested flow-chart for the diagnosis of MPS using blood and urine samples.

\section{The Road to Therapy}

Although attempts to treat MPS diseases have been made with plasmapheresis (Lasser et al., 1975; Nishioka et al., 1979) and vitamin A supplementation (Wannmacher et al., 1984), the first therapeutic approach which proved to bring benefits was bone marrow transplantation (BMT) (Hobbs et al., 1981). The replacement of a patient's bone marrow cells by donor cells with higher enzyme activity is usually followed by a decrease in urinary GAGs, reduction of liver and spleen volumes and improvements in respiratory and cardiac parameters in some MPS types (mainly in MPS I and MPS VI, and potentially MPS VII). BMT (or Hematopoietic Stem Cell Transplantation, HSCT) is not considered beneficial for MPS III and MPS IV, and there is insufficient information about the outcome for MPS II. As mortality and morbidity are high, it is usually not recommended for MPS VI, as for this disease a treatment with enzyme replacement therapy (ERT) is available. The main present indication for BMT/HSCT is in the severe form of

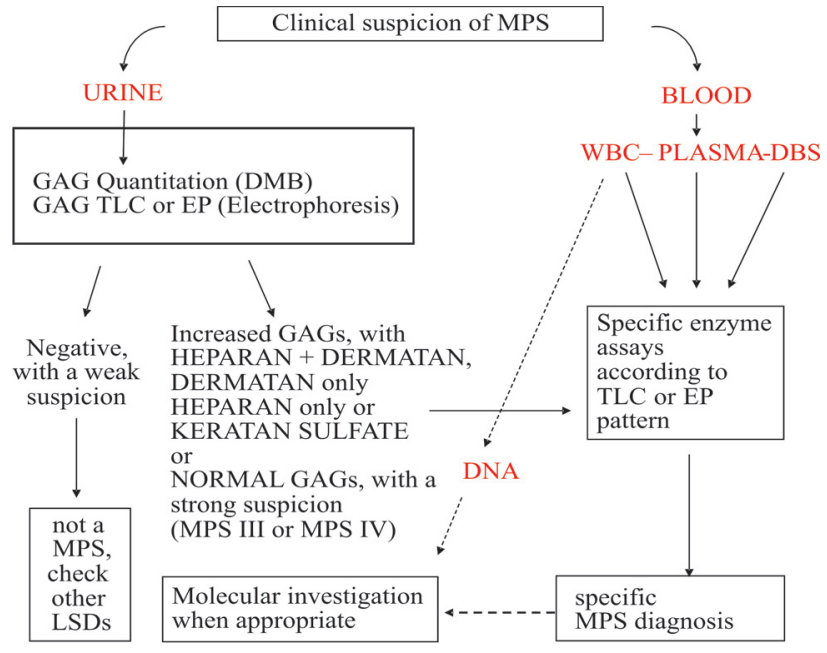

Figure 2 - Proposed flow-chart for the laboratory diagnosis of MPS (dashed line indicates that test is optional for diagnosis). MPS - mucopolyssacaridosis; GAGs - glycosaminoglycans; LSDs - lysosomal storage diseases; DMB - Dimethyleneblue (method used for GAG quantitation); TLC - thin layer chromatography; EP - electrophoresis; WBC - white blood cells; DBS - dried blood spots.

MPS I. In such cases, when BMT/HSCT is performed before the age of two years, donor cells could still migrate to the CNS and produce some enzyme locally, thus preventing the cognitive decline (Prasad and Kurtzberg, 2010).

A major breakthrough in MPS therapy was the development of enzyme replacement therapies for MPS I (Wraith et al., 2004), MPS VI (Harmatz et al., 2006), MPS II (Muenzer et al., 2006) and now for MPS IV A (clinical trials in progress). Although these therapies do not provide a complete cure, the intravenous weekly administration of a recombinant enzyme similar to the missing one brings about measurable and sustainable benefits to the affected patients (Harmatz et al., 2008; Clarke et al., 2009; Muenzer et al., 2011).

\section{Aproaching the Remaining Challenges}

Intravenous ERT markedly decreases urinary GAGs, reduces visceromegaly, improves joint mobility, improves respiratory function, decreases storage in heart muscle, increases growth rate, and improves endurance, among other benefits. However, the enzyme does not remove corneal opacity, does not significantly modify the bone disease, and also has a little impact on cardiac valves. Also, since the intravenously delivered enzyme does not cross the bloodbrain barrier in significant amount, it does not address the spinal cord compression and cognitive decline present in the severe forms of MPS I and MPS II, and is also not an option for the treatment of MPS III patients.

To address the CNS manifestations, intratechal ERT was tested in animal models, with promising results. Pioneer reports on intratechal ERT to treat spinal cord compression in MPS I and MPS VI were made by our group (Munoz-Rojas et al., 2008; Muñoz-Rojas et al., 2010). 
These cases opened the door for clinical trials with intratechal ERT to treat the cognitive decline on MPS I, MPS II and MPS III A (in progress).

Another approach has been the attempt to reduce the build up of GAG storage with the use of genistein, an isoflavone which interferes with GAG synthesis (Piotrowska et al., 2006). Experiments in vitro and with animal models were quite promising, but preliminary results in patients using a relatively low dose did not show measurable benefits (Delgadillo et al., 2011). Clinical trials are presently in progress using higher doses of genistein, and also using other substrate reduction therapy approaches.

Certain observations have led to the proposal that the administration of gentamycin would enable the cellular translation machinery to produce a full-length protein despite the presence of a premature stop codon (Hein et al., 2004). This process, called "read-through", is being explored with other agents and may be an option to modify the severe phenotype usually associated with non-sense mutations to a milder forms.

Gene therapy is also being developed for the MPS, with the view of providing the patient with the correct genetic information for the making of a normal enzyme, and in the near future this approach is expected to progress from pre-clinical studies to clinical trials (Ponder and Haskins, 2007).

The use of encapsulated cells which over-express the deficient enzyme, presently in preclinical development, may be an alternative method for providing an enzyme supply directly to the CNS (Matte et al., 2011). In addition, this treatment could potentially replace the weekly infusions associated with intravenous ERT (Baldo et al., 2012; Piller Puicher et al., 2012).

\section{Early Diagnosis and Newborn Screening}

There is evidence that storage of GAGs begins very early in life (Baldo et al., 2011), and that this storage triggers a cascade of pathogenic events (Bellettato and Scarpa, 2010; Vitner et al., 2010), a process that, once started, could be difficult to reverse. The experience of many doctors suggests that early diagnosis and early treatment bring a better outcome for the MPS patient. This impression has been elegantly documented by McGill et al. (2010) for two MPS VI sibs, and by Gabrielli et al. (2010) for two MPS I sibs. In both reports, one sib was started on the ERT earlier than the other, and observations made when the patients were at the same age indicated a better outcome for the early-treated sib compared to the late-treated one.

These observations, along with the development of high-throughput methods for enzyme analysis using dried blood spots (Wang et al., 2005) or the analysis of GAG species in urine samples (Auray-Blais et al., 2011) are fueling the proposals to initiate newborn screening for MPS diseases, with pilot programs presently being planned. A pilot newborn screening program for MPS VI in a high-inci- dence area of northeastern Brazil is presently in progress and should provide important information about the feasibility of these initiatives.

\section{The MPS Brazil Network}

The rarity of the MPS and the relatively sophisticated methods required for their diagnosis presents a challenge to clinicians attempting to identify and manage these conditions, especially in developing countries. An interesting and innovative project to improve the access of families and health professionals to information, diagnosis and treatment of MPS was set up in Brazil. The MPS Brazil Network is a partnership among medical services in Brazil which deal with MPS patients. The network has a webpage (www.mps.ufrgs.br) which provides a wide range of information and is also a tool for the request of diagnostic tests, which are performed in the network laboratories. A tollfree telephone information service is also in operation, and regular meetings are held to keep families updated with the most recent advances in the field. This initiative is supported with public and private grants, which enable it to provide the services free of charge, making information and diagnostic tests available even for families that usually do not have access to sophisticated healthcare facilities. The consequence of this was that during its first seven years of operation (March/2004 to April/2010) the MPS Brazil Network was able to diagnose over 500 new cases of MPS in Brazil (Table 2), doubling the previous rate of diagnosis.

\section{Final Remarks}

During the last hundred years, remarkable progress has been made in the clinical, biochemical and molecular characterization of the MPS, leading to successful preventive and therapeutic approaches. Despite the recent advances, especially with enzyme replacement therapy

Table 2 - Diagnosis of new cases of MPS by the MPS BRAZIL NETWORK among 2,606 patients investigated between 2004 and 2011 (8 years).

\begin{tabular}{lc}
\hline MPS type & Number of cases \\
\hline MPS I & 92 \\
MPS II & 160 \\
MPS III A & 24 \\
MPS III B & 34 \\
MPS III C & 21 \\
MPS III D & 0 \\
MPS IV A & 49 \\
MPS IV B & 4 \\
MPS VI & 118 \\
MPS VII & 6 \\
MPS IX & 0 \\
Total & 502 \\
\hline
\end{tabular}


developed for several MPS types, some challenges still remain. One major difficulty is how to address the CNS manifestations; another is how to reverse the pathology in hard tissues like bone and heart valves. Progress on the understanding of the physiopathology of these diseases and more advanced treatment approaches such as intratechal ERT, substrate reduction therapy, read-through approach, gene therapy, or therapy using encapsulated modified cells will certainly provide a future for these patients. As early diagnosis and early treatment seem to provide a better outcome, newborn screening may also play an important role in reducing the impact of these diseases.

\section{Acknowledgments}

The author is recipient of a CNPq fellowship (grant $304618 / 2009-8$ ). The newborn screening pilot project is supported by INAGEMP (grant CNPq 57.3993/2008-4). The MPS Brazil Network is funded by grants from CNPq and FAPERGS, and unrestricted grants from Shire and BioMarin. The author expresses his gratitude to the executive team and to the members of MPS Brazil Network for the data provided, and to Dr. Anthony H. Fensom for the careful review of the text and for the valuable suggestions.

\section{References}

Auray-Blais C, Bhérer P, Gagnon R, Young SP, Zhang HH, An Y, Clarke JT and Millington DS (2011) Efficient analysis of urinary glycosaminoglycans by LC-MS/MS in mucopolysaccharidoses type I, II and VI. Mol Genet Metab 102:49-56.

Bach G, Friedman R, Weissmann B and Neufeld EF (1972) The defect in Hurler and Scheie Syndromes: Deficiency of alpha-L-iduronidase. Proc Natl Acad Sci USA 69:2048-2051.

Baldo G, Matte U, Artigalas O, Schwartz IV, Burin MG, Ribeiro E, Horovitz D, Magalhaes TP, Elleder M and Giugliani R (2011) Placenta analysis of prenatally diagnosed patients reveals early GAG storage in mucopolysaccharidoses II and VI. Mol Genet Metab 103:197-198.

Baldo G, Mayer FQ, Burin M, Carrillo-Farga J, Matte U and Giugliani R (2011) Recombinant encapsulated cells overexpressing Alpha-L-Iduronidase correct enzyme deficiency in human mucopolysaccharidosis Type I Cells. Cells Tissues Organs 195:323-329.

Bellettato CM and Scarpa M (2010) Pathophysiology of neuropathic lysosomal storage disorders. J Inherit Metab Dis 33:347-362.

Brailsford JF (1929) Chondro-osteo-dystrophy. Roentgenopgraphic \& clinical features of a child with dislocation of vertebrae. Am J Surg 7:404-410.

Brante G (1952) Gargoylism; A mucopolysaccharidosis. Scand J Clin Lab Invest 4:43-46.

Civallero G, Michelin K, de Mari J, Viapiana M, Burin M, Coelho JC and Giugliani R (2006) Twelve different enzyme assays on dried-blood filter paper samples for detection of patients with selected inherited lysosomal storage diseases. Clin Chim Acta 372:98-102.

Clarke LA, Wraith JE, Beck M, Kolodny EH, Pastores GM, Muenzer J, Rapoport DM, Berger KI, Sidman M, Kakkis
ED, et al. (2009) Long-term efficacy and safety of laronidase in the treatment of mucopolysaccharidosis I. Pediatrics 123:229-240.

Costales F and Garcia-Palacio A (1956) Gargoylism; histochemical demonstration of excess acid mucopolysaccharides in the liver. Rev Cubana Pediatr 28:415-38 (in Spanish).

Delgadillo V, O'Callaghan MD, Artuch R, Montero R and Pineda M (2011). Genistein supplementation in patients affected by Sanfilippo disease. J Inherit Metab Dis 34:1039-1044.

Dorfman A and Lorincz A (1957) Ocurrence of urinary acid mucopolysaccharides in the Hurler Syndrome. Proc Natl Acad Sci USA 43:443-446.

Fan X, Zhang H, Zhang S, Bagshaw RD, Tropak MB, Callahan JW and Mahuran DJ (2006) Identification of the gene encoding the enzyme deficient in mucopolysaccharidosis IIIC (Sanfilippo disease type C). Am J Hum Genet 79:738-744.

Fratantoni JC, Hall CW and Neufeld EF (1968a) The defect in Hurler's and Hunter's syndrome: Faulty degradation of mucopolysaccharide. Proc Natl Acad Sci USA 60:699-706.

Fratantoni JC, Hall CW and Neufeld EF (1968b) Hurler and Hunter syndromes: Mutual correction of the defect in cultured fibroblasts. Science 162:570-572.

Fratantoni JC, Neufeld EF, Uhlendorf BW and Jacobson CB (1969) Intrauterine diagnosis of the Hurler and Hunter syndromes. N Engl J Med 280:686-688.

Gabrielli O, Clarke LA, Bruni S and Coppa GV (2010) Enzyme-replacement therapy in a 5-month-old boy with attenuated presymptomatic MPS I: 5-year follow-up. Pediatrics 125:e183-187.

Harmatz P, Giugliani R, Schwartz I, Guffon N, Teles EL, Miranda MC, Wraith JE, Beck M, Arash L, Scarpa M, et al. (2006) Enzyme replacement therapy for mucopolysaccharidosis VI: A phase 3, randomized, double-blind, placebo-controlled, multinational study of recombinant human $\mathrm{N}$-acetylgalactosamine 4-sulfatase (recombinant human arylsulfatase B or rhASB) and follow-on, open-label extension study. J Pediatr 148:533-539.

Harmatz P, Giugliani R, Schwartz IV, Guffon N, Teles EL, Miranda MC, Wraith JE, Beck M, Arash L, Scarpa M, et al. (2008) Long-term follow-up of endurance and safety outcomes during enzyme replacement therapy for mucopolysaccharidosis VI: Final results of three clinical studies of recombinant human N-acetylgalactosamine 4-sulfatase. Mol Genet Metab 94:469-475.

Hein LK, Bawden M, Muller VJ, Sillence D, Hopwood JJ and Brooks DA (2004) alpha-L-iduronidase premature stop codons and potential read-through in mucopolysaccharidosis type I patients. J Mol Biol 338:453-462.

Hobbs JR, Hugh-Jones K, Barrett AJ, Byrom N, Chambers D, Henry K, James DC, Lucas CF, Rogers TR, Benson PF, et al. (1981) Reversal of clinical features of Hurler's disease and biochemical improvement after treatment by bonemarrow transplantation. Lancet 2:709-712.

Hunter CA (1917) A rare disease in two brothers. Proc R Soc Med 10:104-116.

Hurler G (1919) Über einen Typ multipler Abartungen, vorwiegend am Skelettsystem. Z Kinderheilk 24:220-234.

Hwu WL, Chien YH, Lee NC, Chiang SC, Dobrovolny R, Huang AC, Yeh HY, Chao MC, Lin SJ, Kitagawa T, et al. (2009) Newborn screening for Fabry disease in Taiwan reveals a 
high incidence of the later-onset GLA mutation c.936+919G > A (IVS4+919G > A). Hum Mutat 30:1397-1405.

Imundo L, Leduc CA, Guha S, Brown M, Perino G, Gushulak L, Triggs-Raine B and Chung WK (2011) A complete deficiency of Hyaluronoglucosaminidase 1 (HYAL1) presenting as familial juvenile idiopathic arthritis. J Inherit Metab Dis 34:1013-1022.

Lasser A, Carter DM and Mahoney MJ (1975) Ultrastructure of the skin in mucopolysaccharidoses. Studies performed before and after plasma infusion therapy. Arch Pathol 99:173176.

Lin HY, Lin HY, Chong KW, Hsu JH, Yu HC, Shih CC, Huang $\mathrm{CH}$, Lin SJ, Chen CH, Chiang CC, et al.(2009) High incidence of the cardiac variant of Fabry disease revealed by newborn screening in the Taiwan Chinese population. Circ Cardiovasc Genet 2:450-456.

Maroteaux P, Leveque B, Marie J and Lamy M (1963) A new dysostosis with urinary elimination of chondroitin sulfate B. Presse Med 25:1849-1852.

Matte U, Lagranha VL, de Carvalho TG, Mayer FQ and Giugliani R (2011) Cell microencapsulation: A potential tool for the treatment of neuronopathic lysosomal storage diseases. J Inherit Metab Dis 34:983-990.

Meyer K, Grumbach MM, Linker A and Hoffman P (1958) Excretion of sulfated mucopolysaccharides in gargoylism (Hurler's syndrome). Proc Soc Exp Biol Med 97:275-279.

McGill JJ, Inwood AC, Coman DJ, Lipke ML, de Lore D, Swiedler SJ and Hopwood JJ (2010) Enzyme replacement therapy for mucopolysaccharidosis VI from 8 weeks of age - A sibling control study. Clin Genet 77:492-498.

McKusick VA (1969) The nosology of mucopolysaccharidoses. Am J Med 47:730-747.

Meikle PJ, Hopwood JJ, Clague AE and Carey WF (1999) Prevalence of lysosomal storage diseases. JAMA 281:249-254.

Morquio L (1929) Sur une forme de dystrophie osseuse familiale. Arch méd infants 32:129-135.

Muenzer J, Wraith JE, Beck M, Giugliani R, Harmatz P, Eng CM, Vellodi A, Martin R, Ramaswami U, Gucsavas-Calikoglu M, et al. (2006) A phase II/III clinical study of enzyme replacement therapy with idursulfase in mucopolysaccharidosis II (Hunter syndrome). Genet Med 8:465-473.

Muenzer J, Beck M, Eng CM, Giugliani R, Harmatz P, Martin R, Ramaswami U, Vellodi A, Wraith JE, Cleary $\mathrm{M}$, et al. (2011) Long-term, open-labeled extension study of idursulfase in the treatment of Hunter syndrome. Genet Med. 13:95-101.

Munoz-Rojas MV, Vieira T, Costa R, Fagondes S, John A, Jardim LB, Vedolin LM, Raymundo M, Dickson PI, Kakkis E, et al. (2008) Intrathecal enzyme replacement therapy in a patient with mucopolysaccharidosis type I and symptomatic spinal cord compression. Am J Med Genet 146A:2538-2544.

Muñoz-Rojas MV, Horovitz DD, Jardim LB, Raymundo M, Llerena Jr JC, de Magalhães TS, Vieira TA, Costa R, Kakkis E and Giugliani R (2010) Intrathecal administration of recombinant human $\mathrm{N}$-acetylgalactosamine 4-sulfatase to a MPS VI patient with pachymeningitis cervicalis. Mol Genet Metab 99:346-350.

Natowicz MR, Short MP, Wang Y, Dickersin GR, Gebhardt MC, Rosenthal DI, Sims KB and Rosenberg AE (1996) Clinical and biochemical manifestations of hyaluronidase deficiency. N Engl J Med 335:1029-1033.
Nishioka J, Mizushima T and Ono K (1979) Treatment of mucopolysaccharidosis: Clinical and biochemical aspects of leucocyte transfusion as compared with plasma infusion in patients with Hurler's and Scheie's syndromes. Clin Orthop Relat Res 140:194-203.

Oshima A, Kyle JW, Miller RD, Hoffmann JW, Powell PP, Grubb JH, Sly WS, Tropak M, Guise KS and Gravel RA (1987) Cloning, sequencing, and expression of cDNA for human beta-glucuronidase. Proc Natl Acad Sci USA 84:685-689.

Pennock CA (1976) A review and selection of simple laboratory methods used for the study of glycosaminoglycan excretion and the diagnosis of the mucopolysaccharidoses. J Clin Pathol 29:111-123.

Piller Puicher E, Tomanin R, Salvalaio M, Friso A, Hortelano G, Marin O and Scarpa M (2012) Encapsulated engineered myoblasts can cure Hurler syndrome: Preclinical experiments in the mouse model. Gene Ther 19:355-364.

Piotrowska E, Jakóbkiewicz-Banecka J, Barañska S, Tylki-Szymañska A, Czartoryska B, Wegrzyn A and Wegrzyn G (2006) Genistein-mediated inhibition of glycosaminoglycan synthesis as a basis for gene expression-targeted isoflavone therapy for mucopolysaccharidoses. Eur J Hum Genet 14:846-852.

Piraud M, Boyer S, Mathieu M and Marie I (1993) Diagnosis of mucopolysaccharidoses in a clinically selected population by urinary glycosaminoglycan analysis: A study of 2,000 urine samples. Clin Chim Acta 221:171-181.

Ponder KP and Haskins ME (2007) Gene therapy for mucopolysaccharidosis. Expert Opin Biol Ther 7:1333-1345.

Poorthuis BJ, Wevers RA, Kleijer WJ, Groener JE, de Jong JG, van Weely S, Niezen-Koning $\mathrm{KE}$ and van Diggelen OP (1999) The frequency of lysosomal storage diseases in The Netherlands. Hum Genet 105:151-156.

Prasad VK and Kurtzberg J (2010) Transplant outcomes in mucopolysaccharidoses. Semin Hematol 47:59-69.

Sanfilippo SJ, Podosin R, Langer Jr LO and Good RA (1963) Mental retardation associated with acid mucopolysacchariduria (heparitin sulfate type). J Pediat 63:837-838.

Scheie HG, Hambrick Jr GW and Barness LA (1962) A newly recognized forme frustre of Hurler's disease (gargoylism). Am J Ophthalmol 53:753-769.

Schwartz IV, Pinto LL, Breda G, Lima L, Ribeiro MG, Mota JG, Acosta AX, Correia P, Horovitz DD, Porciuncula CG, et al. (2009) Clinical and biochemical studies in mucopolysaccharidosis type II carriers. J Inherit Metab Dis 32:732-738.

Sly WS, Quinton BA, McAlister WH and Rimoin DL (1973) Beta glucuronidase deficiency: Report of clinical, radiologic, and biochemical features of a new mucopolysaccharidosis. J Pediat 82:249-257.

Spada M, Pagliardini S, Yasuda M, Tukel T, Thiagarajan G, Sakuraba H, Ponzone A and Desnick RJ (2006) High incidence of later-onset Fabry disease revealed by newborn screening. Am J Hum Genet 79:31-40.

Teller WM, Burke EC, Rosevear JW and McKenzie PF (1962) Urinary excretion of acid mucopolysaccharides in normal children and patients with gargoylism. J Lab Clin Med 59:95-101.

Vitner EB, Platt FM and Futerman AH (2010) Common and uncommon pathogenic cascades in lysosomal storage diseases. J Biol Chem 285:20423-20427. 
Wang D, Eadala B, Sadilek M, Chamoles NA, Turecek F, Scott CR and Gelb MH (2005) Tandem mass spectrometric analysis of dried blood spots for screening of mucopolysaccharidosis I in newborns. Clin Chem 51:898-900.

Wannmacher CM, Wajner M, Giugliani R, Costa MG, Giugliani ER and Castro JZ (1984) Clinical and biochemical effects of long-term vitamin A administration to a patient with Hurler-Scheie compound. Braz J Med Biol Res 17:43-47.
Wraith JE, Clarke LA, Beck M, Kolodny EH, Pastores GM, Muenzer J, Rapoport DM, Berger KI, Swiedler SJ, Kakkis $\mathrm{ED}$, et al. (2004) Enzyme replacement therapy for mucopolysaccharidosis I: A randomized, double-blinded, placebo-controlled, multinational study of recombinant human alpha-L-iduronidase (laronidase). J Pediatr 144:581-588.

License information: This is an open-access article distributed under the terms of the Creative Commons Attribution License, which permits unrestricted use, distribution, and reproduction in any medium, provided the original work is properly cited. 